\title{
FROM SUSTAINABLE DEVELOPMENT TO PERSONALISED HEALTHCARE. THE ROLE OF INSTITUTIONS IN THE SUSTAINABLE DEVELOPMENT OF THE HEALTHCARE SYSTEMS
}

\author{
Sergiu Constantin, BATÂR \\ PhD Fellow, SOP HRD/159/1.5/S/133675 Project “Lucian Blaga” University of Sibiu, Romania, sergiu.batar@ulbsibiu.ro
}

\begin{abstract}
The current issues concerning healthcare institutions are generated by: aging of the population; the increase in prevalence of non-communicable diseases, even in low/medium income countries; the continuous increase of indirect costs generated by chronic diseases; the necessity of new- patient-specific oriented therapies; the need of translation of fundamental research into practice; need of applicability of prevention strategies; an important segment of the working population becomes inactive; migration of healthcare professionals.

An essential condition for the sustainable development of any community is the health and the maintenance of the health of its population, and it is essential that the institutions involved in the process adapt to the constant change of the society: the medical academia not only develops health professionals, but conducts research, helps implementing healthcare programmes, develops future strategies, and influences the political systems; the hospitals need to adapt to growing populations; the communities should be involved in out-patient healthcare and prevention of diseases; governmental institutions adapt to the concept of sustainable development in various ways: funding fundamental research, applying nation-wide programmes for prevention and care, help of disadvantaged population, funding medical universities.
\end{abstract}

KEY WORDS: sustainable development; healthcare systems; medical universities

\section{GENERAL ASPECTS}

Ion A. Popescu, Aurelian A. Bondrea and Madalina I. Constantinescu publish in 2005 a synthesis of general and particular aspects of sustainable development in their book "Sustainable development, a Romanian perspective". It was remembered here that starting in 1972, at the Stockholm Conference, that led to formation of the World Commission on Environment and Development, the systematic coordinates for sustainable development should also include elimination of poverty, by providing the population its essential needs: work, food, water, homes and healthcare.

Further, the authors cite the Brundtland Report, which defines several conditions necessary for sustainable development, which include a controlled growth of the population and providing this population places to work, food, energy, homes and healthcare. The authors present important data from the Johannesburg Summit in 2002, when it was estimated that 1,7 billion people do not have access to healthcare services, and about 2,2 million people from developing countries, especially children, die annually due to absence of water and healthcare services.

For the administrators and institutions that are involved in development strategies, including researchers, politicians and business stakeholders, the prediction and prognosis of societal changes are premises for sustainable development, and very important scientific tools. Researchers agree that nowadays the experience and knowledge offer sufficient theoretic, methodological and applicable tools for identifying events and phenomena form nature and society, and also the results of human action. The necessary and sufficient condition for this achievement is the will of the politic class to act in favour of positive evolutions, but also the firm attitude of the civil society, including the academic environment to express in a systematic and organised fashion its opinions and suggestions regarding the viability of the future programmes of development [1].

\section{EXAMPLES OF POLICIES}

1. Nobel prize awarded Amartya Sen cites in 2004 (Development as Freedom- Romanian edition) the example of mortality reduction in Great Britain after 1900, as an example for industrialised countries, that had in the beginning of the century a shorter life expectancy than nowadays low-income countries. The longevity of the population grew intensely in the last century, partially because of social strategies. There were two main periods when the distribution of healthcare services and food supplies to the population increased: during the World Wars. Even the NHS was founded during WW II. Did this correspond to a reduction in mortality rates? It was confirmed that cases of malnutrition almost disappeared, and mortality rates decreased (excepting those caused by war). Life expectancy increased with 7 years during the war decades, compared to the moderate 1-4 year growth in the other decays. But can this increase be explained by the economic growth? The answer appears to be negative, as the GDP had a slow 
increase compared to that of the life expectancy. The author concludes that the public support in favour of social services (including providing of food and healthcare) tend to be responsible for these changes [2].

2. Vladescu and Busoi (2011) compile in their book the stages and institutional actions in the pre-, and post 2007 European Union concerning health policies [3]. The First Health Programme (2003-2007) had three main objectives: increasing knowledge and information in all fields of health, increasing the capacity of fast and coordinated reaction when health status of the population is in danger, and promoting health and prevention by considering responsible factors in all European policies.

The Second Health Programme (2008-2013) was founded having in mind four fundamental principles: universality, access to high quality services, equity and solidarity. Analytical studies were conducted in order to establish the relationship between health status of the population, investments in health and economic growth and development. The strategy for health in the EU in that period had three objectives: promoting a good health status in the context of the ageing population, protecting the population from various threats (for instance epidemics, bio-terrorism, work-place accidents, etc.) and promoting dynamic healthcare systems based on new technologies.

In this context, the European Commission presents data generated by the Eurostat 2006. By 2050 the EU population aged over 65 will increase with over $70 \%$, while the over 80 years old will increase with $170 \%$. This is generated by very low birth rates. This generates a significant decrease in active population, and probably a decrease in the financing the healthcare systems, which in some estimates will represent $25 \%$ of the GDP. It was acknowledged at the highest institutional level that efforts should be increased for prevention and research.

3. Matthias Wismar and Kelly Ernst analysis Health in All Policies in Europe (2010), in Implementing Health in All Policies [4], summarize some working conclusions that, at least partially, influenced future development strategies. Despite important scientific contributions, Europe was still lacking a comprehensive and methodologically pan-European study on the whole-of-government approach and governance tools and frameworks for Health in all policies. Many of the developments take place at local and regional level, and remain unreported. This became more important as federalization, devolution and decentralization in healthcare have assigned more responsibilities to regional and local governments. Examples included situations from Denmark, France, UK and Belgium.

4. Sir Muir Gray reviews in the chapter The 21st Century Healthcare Crisis some important issues that systems will have to take into account [5]: need and demand are increasing faster than the resources, and even if more money would be available, human resources will still be limited, leading to employment of medical graduates from poor countries in rich countries; increasing needs are not only generated by ageing and new diseases, but also by new technologies and innovations; the necessity of defining the subgroups of patients that benefit the most from available procedures; informing the patients about absolute and relative benefits and risks of procedures; there is the need that innovations that enter the healthcare systems decrease costs as well as increase it- and the author cites David Eddy's conclusion that every innovation needs to have its introduction to, or removal from, the healthcare carefully managed; for sustainable healthcare, it is unlikely that resources will be invested in the next ten years at the rate of the last fifty years; there is a NHS strategy Reducing Carbon, Improving Health, which sets a goal of $50 \%$ carbon emissions by 2050 .

The author states that the second healthcare revolution left some problems that won't be solved by scientific advances: failure to prevent the preventable; poor patient safety; variations in quality; waste of resources; inequalities in access and outcome. In the same time, the role of IT and involving the informed population of patients are discussed.

5. Michael J. Klag, Dean of the Johns Hopkins Bloomberg School of Public Health, states the major roles of the medical academic institutions facing the global burden of noncommunicable diseases: as sustainable solutions for healthcare systems are required urgently, academic institutions play a crucial role in this effort. First, they build the healthcare infrastructure. Second, they train leaders across the entire system: providers, administrators, health-system planners and researchers. Third, these institutions conduct the research that generates innovation, as well as building foundations for good policy and prevention strategies. These institutions are qualified to advocate for fair and equitable systems that promote access to care [6].

6. Concerning the way that the academic educational environment should adapt to the changing needs of the population, Julio Frenk, Lincoln Chen and Catherine Michaud write an essay in 2012 about the changes proposed by the Commission on the Education of Health Professionals for the 21st Century: transformative learning and interdependence in professional education [7]. Transformative learning is the highest of three levels, moving from informative to formative to transformative learning. Informative learning involves acquiring knowledge and skills in order to become experts. Formative learning concerns socialising students around values, to produce professionals. Transformative involves developing leadership attributes, to produce change agents. The interdependence concept links six key components in the healthcare system: between local and global systems; between health and education systems; between health professionals and their patients and populations; across categories in the health workforce: intra-, inter-, ant trans-professional collaboration; between the context and competences; and, between teachers and learners, as education becomes a proactive process.

7. Regarding the direction of research, and the concept of individualized medicine, Prof. Thomas Eschenhagen states in 2014 that research is responsible for defining groups of patients that would not benefit from conventional therapies, or those that would respond well. The development of novel therapies requires structures in which the patient is part of the research, and sufficient funds are assured to bring ideas from laboratory to bedside. At the German Centre for Cardiovascular Research this is ensured and ideas from the laboratory can be quickly transferred to the clinic and vice versa, observations on patients and from clinical trials can be checked in the laboratory. Individual research institutions should establish specialized, collaborative frameworks [8].

\section{THE M8 INITIATIVE}

Prof. Ben Canny, one of the organisers of the World Health Summit 2014, states that education is a tool of empowerment, and results in improved health outcomes. 
The M8 initiative comprises 10 medical universities: Charité Universitätsmedizin, Berlin, Kyoto University, Imperial College London, Makerere University, Monash University, National University of Singapore, Peking Union Medical College, Sorbonne Paris Cité, Université de Montreal, and University of São Paulo. This alliance tries to find solutions to educate the next generations to be capable of transforming the healthcare systems to provide for universal health coverage. The areas were the M8 is concentrating are: Global Health Curricula, Community Engagement, and the Social Accountability of Medical Schools [9].

Global Health Curricula. The increase of NCDs prevalence, the increase of international mobility, and a growing desire of the next generations of health practitioners to travel and contribute to solving health problems across the globe, generates the need of this curricula, that is currently lacking from core curricula. The alliance has the necessary expertise for defining such a curricula. Some steps have been made in this direction.

Community Engagement and Education. Changing models of healthcare delivery, which is no longer only at hospital bedsides, mean that students must engage with the community and see patients in settings like ambulatory care, community health and other settings, and even at patients' homes. Resources will need to be diverted away from their traditional sites, to ensure that students have access to patients and learn medicine in a way that is relevant for their future practice, as in universities highly specialized practice and research is carried out.

Social Accountability of Medical Schools. A global movement for determining the social accountability has developed in the last decades. The author cites the example of attending the poor and homeless populations in Sao Paolo that may give lessons for care and engagement with some communities in North America or Australia. The author remembers that an important issue nowadays is the migration of doctors and health professionals that were initially trained in the developing world, and states that a concerted effort to ensure the highquality training of medical practitioners for all communities is necessary.

\section{PHC PROGRAMMES WITHIN THE HORIZON 2020}

General context. Europe $\mathbf{2 0 2 0}$ is a 10-year strategy of the European Union by which the EU sets a goal to increase the economic growth and employment rates. This strategy is intended to overcome the current deficiencies of the current development model, and to create conditions for an intelligent, sustainable and in favour for inclusion- economic growth [10]. In order to achieve this, the European Commission established 5 objectives for 2020 [11]:

1. Employment: $75 \%$ of the 20-64 year olds to be employed;

2. Research\& development/ innovation: $3 \%$ of the EU GDP to be invested in $\mathrm{R} \& \mathrm{D} /$ innovation;

3. Climate change/ energy: greenhouse gas emissions 20\% (or even $30 \%$, if the conditions are right) lower than $1990,20 \%$ of energy from renewables, $20 \%$ increase in energy efficiency;

4. Education: reducing school drop-out rates below $10 \%$; at least $40 \%$ of 30-34-year-olds completing third level education;

5. Poverty / social exclusion: at least 20 million fewer people in or at risk of poverty and social exclusion.
HORIZON 2020 programme has a budged of 70 billion Euros and is systematically designed for founding projects that are capable of finding solutions for achieving the technic, educational and social objectives that the EU member states established within the Europe 2020 Strategy. In this programme, a very important direction is the Societal Challenges having a major component: health, demographic change and wellbeing [12].

In this framework, there are sufficient possibilities for funding research that could solve the issues that we discussed above. From multiple programmes, we selected the PHCpersonalising health and care programmes, of which some are opened, some closed, to exemplify how starting from real, global issues that are highlighted by leading world specialists, international institutions (in this case the European Commission, through the HORIZON 2020) programme- try to assure capable research infrastructure with sufficient funds for solving these issues [13]. We illustrate a few examples, having in mind that those are just a part of the programme, and this is not the only programme that can provide funding for capable research institutions.

1. PHC 1 - 2014: Understanding health, ageing and disease: determinants, risk factors and pathways;

\section{PHC 2 - 2015: Understanding diseases: systems medicine}

3. PHC 4 - 2015: Health promotion and disease prevention: improved inter-sector cooperation for environment and health based interventions

4. PHC 6-2014: Evaluating existing screening and prevention programmes

5. PHC 7 - 2014: Improving the control of infectious epidemics and foodborne outbreaks through rapid identification of pathogens (see also societal challenge 2)

6. PHC $12-2014 / 2015$ : Clinical research for the validation of biomarkers and/or diagnostic medical devices

7. PHC 13 - 2014: New therapies for chronic noncommunicable diseases

8. PHC 15 - 2014/2015: Clinical research on regenerative medicine

9. PHC 17 - 2014: Comparing the effectiveness of existing healthcare interventions in the elderly

10. PHC 19 - 2014: Advancing active and healthy ageing with ICT: Service robotics within assisted living environments

11. PHC 23 - 2014: Developing and comparing new models for safe and efficient, prevention oriented health and care systems

12. PHC 24 - 2015: Piloting personalised medicine in health and care systems

13. PHC 25 - 2015: Advanced ICT systems and services for Integrated Care

14. PHC 26 - 2014: Self-management of health and disease

15. PHC 30 - 2015: Digital representation of health data to improve disease diagnosis and treatment

16. PHC 31 - 2014: Foresight for health policy development and regulation 


\section{CONCLUSIONS}

We illustrated above two examples of institutional approaches for global health issues. In the first, the M8 Initiative, a consortium of Universities, that constitute a part of the leading professionals that annually meet at the World Health Summit, set up a new, more comprehensive organisation that would have the capability of re-thinking the way academic medical institutions should face the future, and how to act in front of more and more challenging societies. In the second example, the PHC programmes of the HORIZON 2020, we illustrated how governmental international institutions act practically facing the current and future perspectives on public health and demographics. In the future, results of these actions will be found not only in scientific publications or meetings, but also in policy, academic development, demographic changes, infrastructure development, administrative reforms, and, probably most important, change and adaptation of the healthcare systems to the current and future issues of the changing population.

In the future, it will be of great interest to study how institutions, from medical universities to healthcare providers, will adapt to the more demanding societies. It will also be necessary to predict the future needs of the European and global population, not only the future demographic evolution, in order to promote solutions, in the same way that in the present the society is reacting to the changes in global health.

\section{ACKNOWLEDGEMENTS}

1. This paper is supported by the Sectorial Operational Programme Human Resources Development (SOP HRD), financed from the European Social Fund and by the Romanian Government under the contract number POSDRU/159/1.5/S/133675.

2. We would like to thank Professor of Internal MedicineCardiology Manitiu Ioan, Chief of Cardiology Clinic of Sibiu County Hospital, for his support and coordination of bedside activity and academic activity. Also, the help and experience of Associate Professor Adela Cojan, public health expert from "Lucian Blaga" University- Sibiu was essential. The expertise in sustainable development provided by Professor Tita Ovidiu from "Lucian Blaga" University was essential in this work. Also, we would like to thank Professor Oprean Constantin for the guidance and more general views on sustainable development that were important for our work.

\section{REFERENCES}

1. Popescu, Ion A., Bondrea, Aurelian A., Constantinescu, M. A., Dezvoltarea durabila, o perspectiva romaneasca. Ed. Economica. Bucuresti, Romania, (2009).
2. Sen, Amartya. Dezvoltarea ca libertate. Ed. Economica. Bucuresti, Romania, (2004).

3. Vladescu, Cristian, Busoi, Cristian. Politici de sanatate in Uniunea Europeana. Ed. Polirom. Iasi, Romania, (2011).

4. Kickbusch, Ilona, Buckett, Kevin, Implementing Health in All Policies Adelaide 2010. Department of Health, Government of South Australia, (2010).

5. Muir, Gray J.A., How to get better value healthcare. Offox Press, Oxford, United Kingdom, (2011).

6. Klag, Michael J. Research for health and sustainable development. World Health Summit, ed. Detlev Ganten, Ilona Kickbusch, 16-17. Berlin, Newsdeskmedia, Buxton press. Germany, (2012).

7. Frenk, Julio, Lincoln C Chen and Catherine Michaud. Balancing public and private roles in the education of health professional in World Health Summit, ed. Detlev Ganten, Ilona Kickbusch, 70-72. Berlin, Newsdeskmedia, Buxton press. Germany, (2012).

8. Eschenhagen, Thomas. Between Polypill and Individualized Medicine-Cardiovascular Research in a Global Contex in World Health Summit Yearbook 2014, ed. Tobias Gerber, 42-43. Berlin, Publisher WHS Foundation GmbH,c/o Charité - Universitätsmedizin. Germany, (2015).

9. Canny, Ben. 2015. Medical education: the M8 initiative in World Health Summit Yearbook, ed. Tobias Gerber, 2627. Berlin, Publisher WHS Foundation GmbH,c/o Charité - Universitätsmedizin, Germany, (2015).

10. Comunicare a Comisiei Europene Europa 2020- O strategie europeana pentru o crestere inteligenta, ecologica si favorabila incluziunii. Bruxelles 3.3.2010- COM(2010) 2020final

11. Comunicare a Comisiei catre Parlamentul European, Consiliu, Comitetul Economic si Social European si Comitetul Regiunilor. Bilanțul Strategiei Europa 2020 pentru o creștere inteligentă, durabilă și favorabilă incluziunii. Bruxelles, 5.3.2014 COM(2014) 130 final

12. Decizie a Consiliului de instituire a programului specific de punere în aplicare a Programului-cadru pentru cercetare și inovare Orizont 2020 (2014-2020). Bruxelles, 30.11.2011. COM (2011) 811 final-2011/0402 (CNS).

13. HORIZON 2020 - WORK PROGRAMME 2014-2015. 8. Health, demographic change and wellbeing. (European Commission Decision C (2014)9294 of 10 December 2014. Accessed on ec.europa.eu in 20 Feb 2015. Available at

http://ec.europa.eu/research/participants/portal/desktop/en/ opportunities/h2020/topics/2273-phc-30-2015.html\#tab1 